\section{Novos movimentos sociais e extensão universitária: para uma configuração democrática de saberes}

Maria del Carmen Cortizo

Professora e pesquisadora da

Universidade de Santa Catarina, Brasil.

maria.ufsc@gmail.com
Integración de la docencia y la extensión /

Perspectivas

RECEPCIÓN: 23/06/16

ACEPTACIÓN FINAL: 23/08/16

\section{Resumo}

Este artigo apresenta algumas reflexões acerca das relações entre os novos movimentos sociais e a universidade através da extensão, salientando as possibilidades que este tipo de atividade traz para uma construção democrática de saberes. Desenvolvemos as nossas análises em três momentos: em primeiro lugar caracterizamos alguns aspectos da atual crise da universidade. Em segundo lugar situamos teoricamente o protagonismo dos novos movimentos sociais desde uma perspectiva não determinista partindo do pressuposto de que as relações sociais estão marcadas hoje pela pluralidade de grupos e identidades não homogeneizáveis, com linguagens, saberes, agendas, características e demandas próprias. Finalmente, tratamos possibilidades abertas pela extensão na direção da superação da crise da universidade no diálogo com questões e saberes colocados em pauta pelos novos movimentos sociais.
Palavras-chave

- Novos movimentos sociais

- Extensão universitária

- Processos de democratização

\section{Resumen}

Este artículo presenta algunas reflexiones sobre la relación entre los nuevos movimientos sociales y la universidad, a través de la extensión, enfatizando las posibilidades que este tipo de actividad tiene para una construcción democrática del conocimiento. Desarrollamos nuestro análisis en tres etapas: en primer lugar, caracterizamos algunos aspectos de la crisis actual de la universidad. En segundo lugar, situamos el papel de los nuevos movimientos sociales teóricamente, desde una perspectiva no determinista partiendo del presupuesto de que las relaciones sociales se caracterizan hoy por la pluralidad de grupos no homogeneizables, con identidades, lenguajes, saberes, agendas, características y demandas propias. Finalmente, tratamos posibilidades abiertas por la extensión en la dirección de la superación de la crisis de la universidad en el diálogo con cuestiones y conocimientos incluidos en la agenda por los nuevos movimientos sociales.

Palabras clave

- Nuevos movimientos sociales

- Extensión universitaria

- Procesos de democratización
Para citación de este artículo

Cortizo, M. C. (2016). Novos movimentos sociais e extensão universitária: para uma configuração democrática de saberes. En Revista +E versión digital, (6), pp. 74-83. Santa Fe, Argentina: Ediciones UNL. 


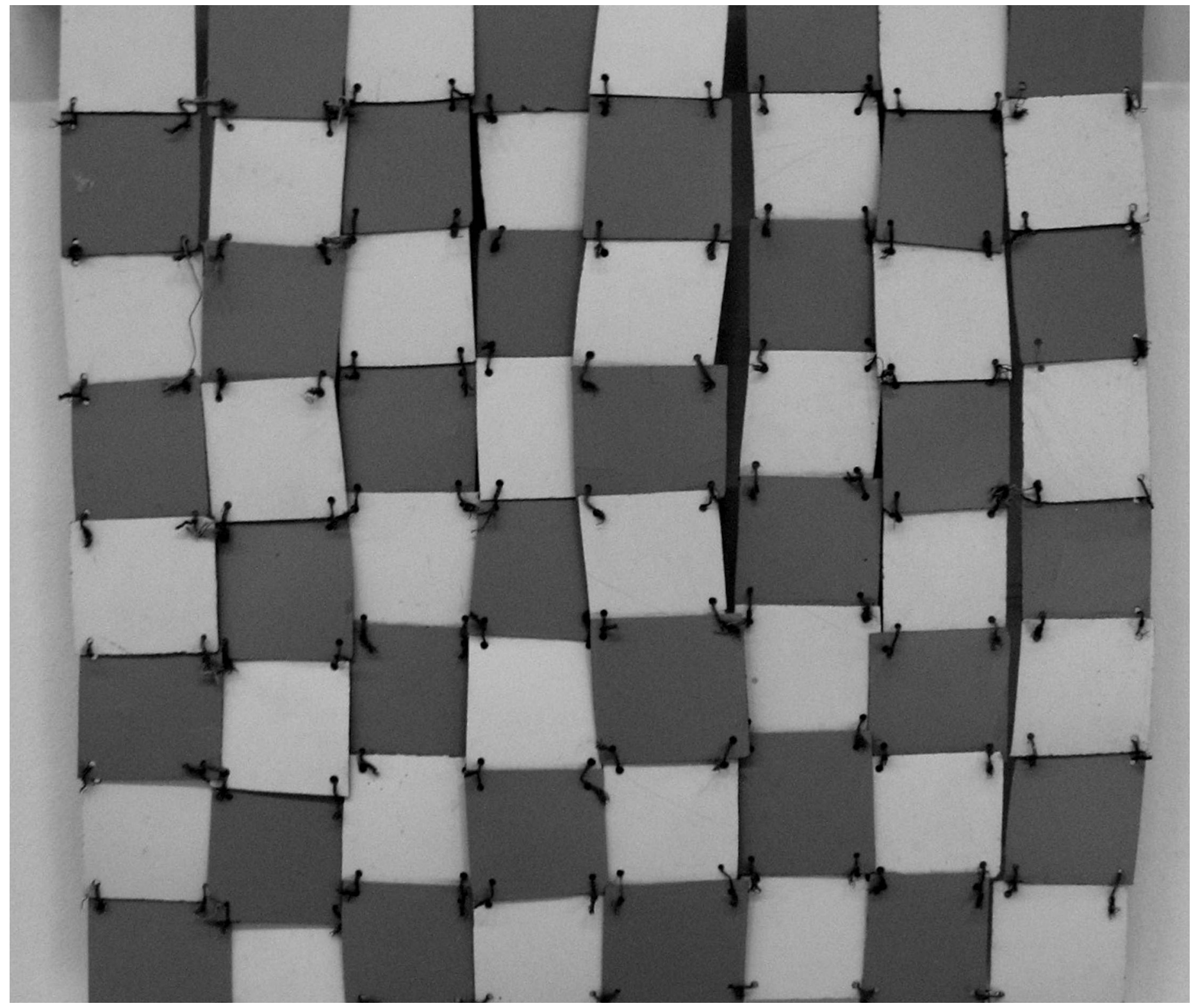

(c) Cecilia lucc 


\section{Introdução}

Este artigo apresenta algumas reflexões acerca das relações entre a universidade e os novos movimentos sociais através da extensão universitária. Teoricamente se parte de pressupostos que afirmam a pluralidade do social e novas possibilidades de articulação dos antagonismos em um projeto democrático radical. As análises se apresentar em três tópicos: a crise da universidade; o protagonismo dos novos movimentos sociais, e as possibilidades democratizadoras da extensão universitária.

\section{A atual crise da universidade}

Até faz poucas décadas atrás o conhecimento produzido nas universidades se caracterizava pela distinção absoluta entre o conhecimento científico e outros tipos de conhecimentos considerados não-ciência e, portanto, alheios ao processo de produção científico que outorga legitimidade à universidade. Mas, hoje é comum escutar falar sobre a crise ou as crises da universidade: financeira, organizacional, institucional, de hegemonia. Provavelmente na raiz de todas encontremos a própria incerteza sobre a sua finalidade e objeto.

Chauí (2003) considera a universidade como uma instituição social diferenciada e autônoma de caráter democrático e republicano, consequentemente o seu pleno desenvolvimento só poderá acontecer numa sociedade democrática e republicana e num Estado com as mesmas características. As transformações políticas acontecidas no Brasil nos últimos anos têm reforçado o caráter instrumental, não somente da universidade, mas da educação em todos os seus níveis, passando ao primeiro plano as "estratégias balizadas pelas idéias de eficácia e de sucesso no emprego de determinados meios para alcançar o objetivo particular que a define". (Chauí, 2003:6)

Assim, perdem interesse os questionamentos sobre a relação com o processo democrático da sociedade, sobre a legitimidade, sobre as contradições sociais e políticas internas e externas, sobre as suas finalidades últimas, assumindo relevância as questões da eficiência, da massificação do conhecimento, dos resultados imediatos, da produtividade, da pulverização das atividades que afoga o trabalho intelectual.

Nesse marco, a universidade deve enfrentar complexos dilemas: Como lidar com as demandas públicas e com as demandas privadas externas, e ao mesmo tempo com as divisões, as diferenças e os conflitos que nada mais são do que expressão interna da complexa realidade social na qual se insere? Uma questão fundamental para pensar a universidade é refletir sobre o que
Chauí (2001) designa como as duas vocações desta instituição: a vocação científica e a vocação política, ou em outras palavras: saber e poder. A autora coloca dois exemplos —um clássico e um contemporâneo- sobre as possíveis relações entre o saber e o poder. O exemplo clássico é o dos gregos, com o surgimento da democracia surge a necessidade de formar um cidadão capaz de exercer seus direitos fundamentais, assim o conhecimento dos negócios da cidade deveria estar ao alcance de todos aqueles chamados a deliberar na e sobre a polis. Os gregos inventaram a política, o espaço público das instituições públicas, as decisões tomadas em público pelo voto, separaram o espaço público e o privado, a autoridade religiosa e o poder político, criaram a filosofia.

"Inventaram ao mesmo tempo, a idéia ocidental do poder e da razão e criaram escolas (...) para a formação do cidadão e do sábio com uma única educação e uma única vocação". (Chauí, 2001)

A vocação política era inseparável da vocação pelo conhecimento, a formação política e a formação filosófica constituiam elementos do mesmo processo de formação cidadã.

Essa concepção de formação se quebrou com o predomínio dos governos autocráticos dos impérios monárquicos, nos quais a formação do cidadão não é mais necessária para o governo da sociedade, longe disso aparece como um empecilho ao desenvolvimento do poder político absoluto. Ainda assim, não se desconhece a importância da relação saber-poder, mas a mesma adquire um outro significado, a ponto tal que as universidades medievais surgem para formular as teorias jurídicas e teológicas dos fundamentos do poder político.

Na modernidade a universidade retoma a afirmação do seu caráter público (o conhecimento não deve ser privilégio de corporações de ofício) e coletivo (o conhecimento não pode ser obra de uns poucos), mas as duas vocações permanecem separadas.

O exemplo contemporâneo se refere aos eventos de 1968, desencadeados por diversos movimentos sociais (movimento pelos direitos civis, movimentos estudantis, movimentos guerrilheiros da América Latina, movimentos libertários da antiga Europa do Leste, movimento feminista, movimento negro, e outros). Em boa parte deles o ponto de partida foram as universidades como fonte de conhecimentos e de práticas novas.

Também existem exemplos da face escura da relação entre a vocação política e a vocação científica da universidade, como são as pesquisas nucleares e genéticas ao serviço do poder armamentista. O caráter da relação dependerá do projeto societário no qual a universidade se encontre inserida, e será marcado pelo fato de tratar-se de uma instituição social que exprime no seu interior a 
realidade das divisões, das diferenças e dos conflitos.

Na visão da Chauí a universidade brasileira:

"Está sem um projeto nacional, não parece disposta a refletir sobre as suas vocações, a perceber em que são compatíveis e incompatíveis, não parece disposta a superar a tradição do avestruz (...) erguer a bandeira da vocação científica sempre que a vocação política questiona a primeira, e a erguer a bandeira da vocação política sempre que os resultados da docência e da pesquisa são medíocres. Não há certeza nas relações com as várias esferas do poder político. Não há clareza na definição das formas de relação com a sociedade, a universidade oscilando entre a idéia de extensão universitária e a de exclusão universitária, entre a identificação do social com as empresas privadas com os partidos políticos". (Chauí, 2001:128-129)

Como veremos mais adiante dentre as três típicas atividades da universidade (ensino, pesquisa, extensão) é a extensão que poderá constituir-se em espaço de articulação das duas vocações e podendo reforçar projetos societários conservadores ou emancipatórios.

\section{O protagonismo dos novos movimentos sociais.}

A sociedade, objeto e objetivo do ensino, pesquisa e extensão da universidade, mudou radicalmente nas últimas décadas, e um dos fatores dessa mudança foi o surgimento e fortalecimento dos novos movimentos sociais, ao tempo em que o movimento operário perdia a sua posição privilegiada nos processos sociais de emancipação. A difusão social da produção contribuiu para desocultar novas formas de opressão o que facilitou a emergência de novos sujeitos sociais e de novas práticas de mobilização social (Sousa Santos, 1997).

Como explicita Sousa Santos (1997:258) a novidade maior dos novos movimentos sociais reside em que constituem tanto uma crítica da regulação social capitalista quanto uma crítica da emancipação social socialista (tal como foi definida pelo marxismo). As novas formas de opressão denunciadas extravasam as relações de produção e nem sequer são específicas delas, como por exemplo, a guerra, a poluição, o machismo, o racismo, a intolerância religiosa, a homofobia, o produtivismo. Essas formas de opressão não atingem especificamente uma classe social e sim grupos sociais transclassistas ou mesmo a sociedade no seu conjunto. Consequentemente não há uma pré-constituição estrutural dos grupos ou movimentos de emancipação, assim o movimento operário não tem uma posição privilegiada pré-determinada nos processos sociais de transformação.

Neste contexto, segundo Laclau:

"As categorias de "classe trabalhadora", "pequeno burguês", etc., adquirem um significado cada vez mais reduzido como forma de entendimento da identidade global dos agentes sociais. O conceito de 'luta de classes', por exemplo, não é correto nem incorreto - ele é, simplesmente, insuficiente para descrever os conflitos sociais contemporâneos". (1986:2)

A noção clássica de subjetividade perdeu a sua auto-suficiência como princípio explicativo das ações dos sujeitos já que não podemos nos referir mais aos sujeitos sociais como se fossem unidades racionais absolutamente transparentes que transmitem um significado homogêneo a todas as suas ações. Em outras palavras:

"devemos abordar o agente social como uma pluralidade, dependente de várias posições de sujeito, através das quais o indivíduo é constituído, no âmbito de várias formações discursivas", deste modo, a característica central dos novos movimentos sociais é que "um conjunto de posições de sujeito a nível de local de residência, aparatos institucionais, várias formas de subordinação cultural, racial e sexual, tornaram-se pontos de conflito e mobilização política". (3)

Mas, como afirma Laclau, no meio dessa multiplicação de lutas sociais:

"Não há nenhuma posição de sujeito cujas conexões com outras posições possam ser permanentemente asseguradas; e, por conseqüência, não há nenhuma identidade social integralmente adquirida que não esteja sujeita, em maior ou menor escala, à ação de práticas articulatórias". (4)

Essas práticas articulatórias operam em contextos de projetos antagônicos em luta pela hegemonia. Neste sentido, as formas de articulação dos antagonismos são a resultante de uma luta hegemônica e do projeto hegemônico que essa luta objetiva. A fim de avançar nas nossas considerações sobre as articulações possíveis entre os movimentos sociais e a universidade, precisamos realizar algumas considerações sobre o "projeto" societário. Compartilhamos das reflexões de Dagnino (2006) quem alerta sobre os riscos de adotar uma concepção simplista do processo de construção democrática que se sustenta numa visão apologética da sociedade civil. Segundo esta visão a sociedade civil concentraria as virtudes democratizantes em contraposição 


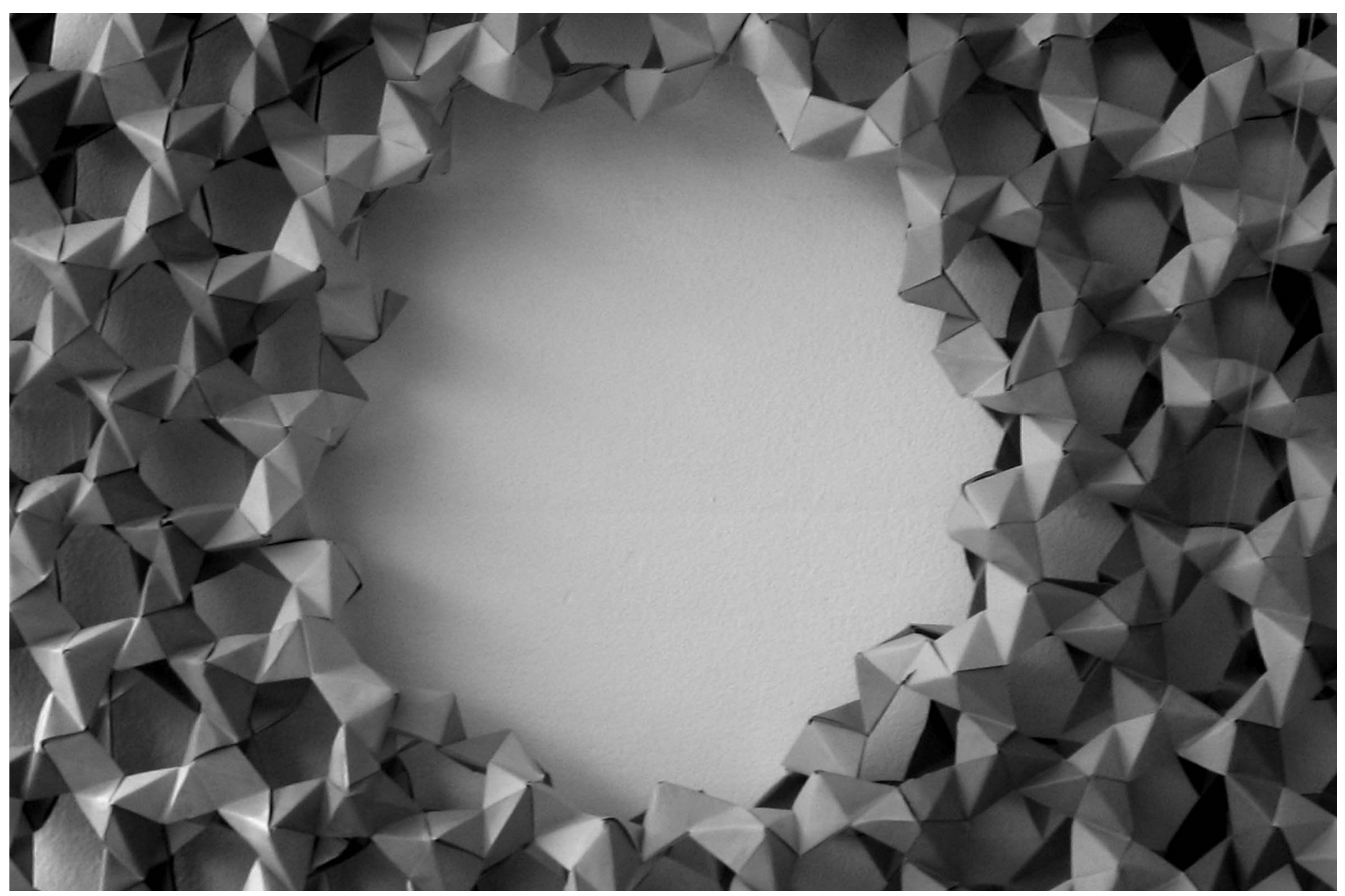

(C) Cecilia Iucci

ao Estado. Existem diferentes projetos no interior da sociedade civil que é necessário identificar a fim de ter uma compreensão mais complexa e realista do social. Esses projetos que se desenvolvem tanto no espaço da sociedade civil quanto do Estado podem ter caráter democrático, mas também autoritário. O processo de construção democrática é resultado de

"um intrincado jogo de forças em disputa, que se trava nas diversas arenas e que inclui uma gama muito diferenciada de atores". (Dagnino, 2006:16)

Entre esses atores se encontram os movimentos sociais, uma pluralidade de grupos e identidades não homogeneizáveis, com linguagens, saberes, agendas, características e demandas próprias. A existência mesma dos movimentos sociais e das suas lutas produz a multiplicação tanto das exigências sociais concretas colocadas em pauta e quanto da natureza das mesmas, e por tanto dos espaços públicos nos quais esses múltiplos conflitos se deflagram. Esse processo leva ao necessário reconhecimento da inexistência de um único conflito social. Encontramos-nos perante um alargamento da política desde que a politização do social, do cultural e até do pessoal abre um campo imenso para o exercício da cidadania, mostrando a insuficiência da concepção liberal que restringe a política ao espaço definido como o político-estatal, em contraposição ao privado-não estatal.

Seguindo Laclau e Mouffe pensamos que a política, enquanto criação, reprodução e transformação das relações sociais, não pode ser localizada em um determinado lugar do social. O político é o problema da instituição do social, da sua definição e articulação hegemônica no meio dos antagonismos (Laclau E Mouffe, 1987; Mouffe, 1999). Então, quais são as condições de emergência dos novos movimentos sociais enquanto ação coletiva encaminhada a lutar contra as desigualdades questionando as relações de subordinação?

O caráter de servo ou escravo, por exemplo, não designa por si mesmo situações de antagonismo. $O$ antagonismo social se constitui somente quando aparece um discurso exterior que permite a subversão da categoria de "servo" ou "escravo", no exemplo, a possibilidade histórica de surgimento do antagonismo 
aparece somente com o reconhecimento e declaração dos "direitos inerentes a todo ser humano", com a Revolução Francesa. Somente quando o discurso democrático se encontrou disponível para articular as diferentes formas de resistência à subordinação é que apareceram as condições de possibilidade de luta contra os diferentes tipos de desigualdade.

Quando os princípios democráticos de igualdade e liberdade se impõem como matriz do imaginário social, produz-se a revolução democrática, chega ao fim o tipo de ordem social que encontrava o seu fundamento na vontade divina, da qual a sociedade desigual e hierarquicamente constituída era a realização histórica concreta. O momento fundacional desse novo discurso democrático se encontra na Revolução Francesa: foi então que surgiu pela primeira vez a possibilidade de afirmação do poder soberano do povo.

A Declaração dos Direitos do Homem e do Cidadão proporcionou as condições discursivas que permitiram considerar as diversas formas de desigualdade como ilegítimas e antinaturais, colocandoas como formas de opressão. Dessa primeira crítica às formas de desigualdade no exercício dos direitos políticos se produz um deslocamento, através dos discursos socialistas, para a crítica da desigualdade econômica, o que conduz ao questionamento de outras formas de subordinação e à reivindicação de novos direitos, abrindo-se um irreversível processo de multiplicação geométrica de novas reivindicações.

A declaração de cada novo direito abre o espaço discursivo para a reivindicação de outros novos direitos e assim sucessivamente, num processo de expansão indefinido e não determinado aprioristicamente. As conseqüências sociais e as possibilidades históricas de novas lutas por novos direitos dependerá sempre das articulações hegemônicas que cada sociedade esteja em condições de produzir, por isto não é possível estabelecer nem ritmos temporais, nem direções determinadas, nem sujeitos privilegiados nos processos de transformação social.

Os novos antagonismos — cujo surgimento possibilita a configuração de um novo contexto discursivo- podem apresentarse em duas variantes fundamentais: 1) pode tratar-se de relações de subordinação que já existiam e que, em virtude de uma modificação ou alargamento do imaginário democrático aparecem rearticuladas como relações de opressão; 2) o antagonismo pode surgir quando, por exemplo, direitos adquiridos ou relações sociais que não tinham sido constituídas originariamente como relações de subordinação passam a sê-lo, com a modificação das circunstâncias sociais, por exemplo, quando, depois de um rearranjo de forças políticas, uma minoria começa a ser discriminada. Mas, em todo caso, sempre é o surgimento de um discurso, convertido em senso comum, que abre a possibilidade de que as resistências contra a opressão assumam o caráter de lutas coletivas. Este é o caso dos chamados novos movimentos sociais. Eles são, segundo Laclau e Mouffe (1987:179), a extensão da

\section{CG}

as novas lutas sociais
por direitos novos ou
pelo efetivo exercício de
direitos já reconhecidos
não têm necessariamente
um caráter progressista,
é um erro pensar que se
situam espontaneamente
no contexto de projetos
políticos de esquerda

revolução democrática a toda uma nova série de relações sociais. No terreno da democracia se abre um leque de possibilidades, a partir das quais é necessário construir articulações hegemônicas visando ao projeto de democracia plural e radical, já que os diferentes movimentos sociais (em sentido lato) que se produzem no seio da sociedade não têm por si pré-determinada uma potencialidade democratizadora específica, por exemplo, existem movimentos ecologistas, anticapitalistas, anti-industriais, autoritários, libertários, socialistas, reacionários, etc.

As novas lutas sociais por direitos novos ou pelo efetivo exercício de direitos já reconhecidos não têm necessariamente um caráter progressista, é um erro pensar que se situam espontaneamente no contexto de projetos políticos de esquerda. O mais relevante deste ponto de vista é a afirmação da potencialidade germinal desses antagonismos para articular-se entre si dentro de um projeto hegemônico de democracia plural e radical. Em todos eles se questiona algum ou vários dos critérios de inclusão/exclusão que tipificam o modelo do contrato social moderno. Eis a sua potencialidade, o que lhes outorga sentido, e não o lugar social do 
qual provém, já que não existe lugar privilegiado de implementação da transformação social, tudo dependerá da existência de um projeto político articulador que lute pela hegemonia.

Hoje nos encontramos perante o projeto hegemônico do liberalconservadorismo, que se articula em torno da definição individualista dos direitos e de uma concepção negativa de liberdade. Produziuse um rearranjo nos critérios de inclusão/exclusão da formação hegemônica anterior —o Estado de bem-estar- os que ontem foram sujeitos titulares de direitos sociais exigíveis perante $o$ Estado hoje se tornaram —dentro desse discurso—os "parasitas" da seguridade social.

Mas, para que qualquer tipo de projeto democrático radical e plural seja possível, torna-se necessária, como colocam Laclau e Mouffe:

"La construcción de un nuevo "sentido común" que cambie

la identidad de los diversos grupos, de modo tal que las demandas de cada grupo se articulen equivalencialmente con las de los otros -en palabras de Marx: "que el libre desarrollo de cada uno sea la condición para el libre desarrollo de todos los demás". O sea, que la equivalencia es siempre hegemónica en la medida en que no establece simplemente una "alianza" entre intereses dados, sino que modifica la propia identidad de las fuerzas intervinientes en dicha alianza". (1987:207)

Cabe nesse contexto o reconhecimento de outras formas de saber e a afirmação da universidade como ponto privilegiado de encontro entre eles. Assim a hegemonia da universidade no que diz respeito à produção de conhecimento científico deixa de residir no caráter único e exclusivo do saber que produz e transmite para passar a residir no caráter único e exclusivo da configuração de saberes que possibilita (Sousa Santos, 2005).

Essas novas configurações de saberes surgidas da relação da universidade com a complexidade do social —segundo até aqui apresentado- não se inserem necessariamente em processos democratizadores, isso dependerá do projeto que lhe outorga sentido. Como veremos a continuação a extensão universitária não é automaticamente emancipatória, poderá continuar sendo perversamente assistencialista, servindo de reprodutora de subalternidade ao projeto neoliberal, não podemos esquecer que o neoliberalismo tem-se apropriado do discurso da participação e da cidadania, mas com um significado que oculta os antagonismos e opaca as diferenças (Dagnino, 2006:17).

\section{Extensão e projeto democrático}

A partir de 1987 com a criação do Fórum de Pró-Reitores de Extensão das Universidades Públicas Brasileiras (2001), se afirma no Brasil uma nova visão das atividades de extensão que se consolida no Plano Nacional de Extensão Universitária de 1998, atualizado em 2001.
O Plano foi elaborado pelo mencionado Fórum e pela Secretaria de Educação Superior do Ministério da Educação e do Desporto, e anunciava refletir "o compromisso da universidade com a transformação da sociedade brasileira em direção à justiça, à solidariedade e à democracia", a fim de participar na elaboração e execução de políticas públicas que tenham a cidadania e o cidadão como suas principais referências.

Os princípios fundamentais contidos no Plano são:

1) A extensão se entende, para além do clássico assistencialismo, como função inerente à universidade articulada com o ensino e a pesquisa em relação direta com a organização e assessoramento dos novos movimentos sociais. Espaço privilegiado de produção do conhecimento significativo para a superação das desigualdades sociais existentes.

2) Afirma-se a necessidade de institucionalização da extensão, a fim de encontrar junto com as atividades de ensino e pesquisa formas de atender à maioria da população, através de um processo de educação superior crítica, com competência técnica e política, direcionada ao estudo dos grandes problemas, propiciando a participação das populações na condição de sujeitos, e não na de meros espectadores.

3) A relação com a população passa a ser encarada como a "oxigenação necessária" à vida acadêmica, e a produção do conhecimento. Via extensão, se faria na troca de saberes sistematizados, acadêmico e popular, tendo como conseqüência a democratização do conhecimento.

4) A universidade deve estar voltada para os interesses e as necessidades da maioria da população, conforme os seguintes princípios básicos:

- a ciência, a arte e a tecnologia devem alicerçar-se nas prioridades do local, da região, do país;

- a universidade não pode se imaginar proprietária de um saber pronto e acabado, que vai ser oferecido à sociedade, mas, ao contrário, exatamente porque participa dessa sociedade, a instituição deve estar sensível a seus problemas e apelos, quer através dos grupos sociais com os quais interage, quer através das questões que surgem de suas atividades próprias (ensino, pesquisa e extensão);

- a universidade deve participar dos movimentos sociais, priorizando ações que visem à superação das atuais condições de desigualdade e exclusão existentes no Brasil;

- a ação cidadã das universidades não pode prescindir da efetiva difusão dos saberes nelas produzidos, de tal forma que as populações cujos problemas tornam-se objeto da pesquisa acadêmica sejam também consideradas sujeito desse conhecimento, tendo, portanto, pleno direito de acesso às informações resultantes dessas pesquisas;

- a prestação de serviços deve ser produto de interesse acadêmico, científico, filosófico, tecnológico e artístico do ensino, 
pesquisa e extensão, devendo ser encarada como um trabalho social, ou seja, ação deliberada que se constitui a partir da realidade e sobre a realidade objetiva, produzindo conhecimentos que visem à transformação social;

- a atuação junto ao sistema de ensino público deve se constituir em uma das diretrizes prioritárias para o fortalecimento da educação básica através de contribuições técnico-científicas e colaboração na construção e difusão dos valores da cidadania.

5) A partir dessas premissas é que se considera a atividade de extensão, pelo potencial da comunidade universitária (professores, alunos, técnicos), um instrumento incomparável de mudança nas próprias instituições onde se desenvolve e nas sociedades onde essas instituições estiverem inseridas. Resultado dessas reflexões é que se considera importante consolidar essa prática dentro das instituições.

Apesar das diretrizes e metas traçadas no Plano a extensão universitária não tem seguido majoritariamente o caminho indicado. E aqui retomamos uma questão inicialmente colocada: a universidade é uma instituição social e como tal é parte dos conflitos presentes na sociedade. Ainda concebendo a extensão universitária como espaço de transformação social não existem direções predeterminadas para essa transformação, dependerá da articulação particular dentro de um projeto. Não existe nada de automático na relação entre a ciência e o conhecimento popular, ou o senso comum, essa relação poderá —e é essa a nossa principal afirmação— constituir-se em elemento de transformação emancipatória, mas isso não é necessário.

Nesse sentido podemos afirmar que as atividades de extensão poderão abrir possibilidades na direção da superação da crise da universidade desde que propiciem o diálogo com questões e saberes colocados em pauta pelos novos movimentos sociais, permitindo o redimensionamento da relação entre política e conhecimento. Entendendo a extensão — tal e como faz o Plano- como processo educativo que articula o ensino e a pesquisa de forma indissociável e viabiliza a relação transformadora entre universidade e sociedade, este tipo de atividade detém as condições para congregar cidadãos (da comumente chamada comunidade externa) e universitários em comunidades interpretativas que superem as usuais interações em que as pessoas são forçadas a renunciar à interpretação da realidade social que lhes diz respeito, através de complexos processos de incorporação crítica dos elementos emancipatórios desses saberes considerados a priori como não-ciência.

Uma das grandes questões que deve ser enfrentada é que embora exista um aparente consenso sobre a definição e os alcances da extensão universitária, não existe consenso sobre o projeto societário no qual a universidade e, portanto a extensão está imersa. Segundo o nosso ponto de vista não poderia existir consenso já que se trata da presença na sociedade e no Estado de projetos antagônicos em luta pela hegemonia.

Um projeto de democracia radical e plural deverá construir um novo senso comum que mude as identidades de modo tal que as demandas de um grupo se articulem equivalencialmente com as outras. Um dos grandes desafios neste sentido é que até faz poucas décadas atrás o conhecimento produzido nas universidades se caracterizava pela distinção absoluta entre o conhecimento científico e outros tipos de conhecimentos considerados como "nãociência" e, portanto, alheios ao processo de produção científico legitimador da universidade enquanto instituição social.

O paradigma herdado do modelo da ciência moderna ainda predominante impede alternativas de projetos de mudança social que pretendam a incorporação transformadora do senso comum ou de concepções de mundo consideradas não científicas. Como diz Nun: "éste es finalmente el asunto: en política, toda discusión sobre el sentido común es una discusión sobre la democracia". Mas o inverso, podemos acrescentar, também é verdadeiro: toda discussão sobre a democracia deve ser uma discussão sobre o senso comum. No sentido da argumentação de Nun:

"Tanto en el Este como en el Oeste, la retórica política acabó apropiándose del argumento de Rousseau: la ley debe fundarse en la voluntad popular y no en una razón iluminada porque únicamente pueden ser obligados por ella, como personas libres, los hombres y las mujeres que contribuyen a hacerla. Sólo que asistimos a una profecía autocumplida: por un lado, las diversas formas de institucionalización de la política han coincidido en una desvalorización sistemática de los componentes de sentido común de esa múltiple y heterogénea voluntad popular; y, por el otro, la falta de información y el escaso interés por la política del ciudadano medio son esgrimidos como justificación palmaria de los propios mecanismos que en gran medida los provocan, esto es, como prueba de la inviabilidad de una democracia genuinamente participativa.

(...) Repensar las relaciones entre las teorías sociales, las ideologías políticas y el sentido común popular me parezca condición necesaria para una búsqueda de alternativas institucionales que, al darles una materialidad respetuosa de su autonomía relativa, faciliten "transiciones auténticas" que permitan su comunicación y su confrontación". (1989:99)

O senso comum, enquanto conceito, surge no século XVIII e representa o combate da burguesia contra o ancien régime. $O$ senso burguês se apresenta como um senso natural, razoável, prudente, e acaba por converter-se no senso médio e universal. Contra esse senso comum lutam as ciências sociais nascidas no século XIX, em uma complexa relação de aceitação-rejeição. 


\section{6}

\section{o paradigma herdado do modelo \\ da ciência moderna impede a \\ incorporação transformadora do \\ senso comum ou de concepções de \\ mundo consideradas não científicas}

Algumas correntes teóricas salientaram seus aspectos positivos, como o conceito de consciência coletiva elaborado por Durkheim, ou o conceito de opinião pública próprio da ciência política. Outras correntes, por sua vez, salientaram a negatividade do senso comum, o exemplo mais forte neste sentido é o conceito de ideologia elaborado pela teoria marxista, que envolve também o senso comum (Sousa Santos, 1991).

Dentro da tradição marxista é com Gramsci se abre a possibilidade de reconsideração do senso comum visando um projeto hegemônico de caráter socialista. O interesse de Gramsci pela cultura das classes subalternas - a "religião do povo"- e pela criação de uma nova cultura provém da certeza de que a cultura é sempre politicamente funcional aos interesses das classes. Para ele o antagonismo com o capitalismo e a sua derrubada exigem a criação de uma nova visão do mundo.

Nos Quaderni del Carcere Gramsci se refere ao senso comum como a "filosofia dos não filósofos", as concepções de mundo absorvidas acriticamente nos diferentes âmbitos sociais e culturais nos quais se desenvolve a individualidade moral do homem médio (Gramsci, 1981:1396).

Cada grupo social tem o seu senso comum, a sua própria concepção de mundo difundida e aceita. Segundo Gramsci, esse senso comum é desarticulado, não pode constituir uma ordem intelectual unificada e coerente, é dogmático e conservador. Porém, isto não significa que não existam elementos de verdade nesse tipo de conhecimento; esses elementos devem ser recuperados e reconstruídos em um outro nível: através da filosofia da práxis, que se constitui como crítica ao senso comum. Assim, de acordo com Gramsci, não se trata de introduzir um conhecimento científico, uma ciência nova na vida das pessoas, mas de tornar crítica uma atividade cognitiva já existente (1383). A experiência concreta dos setores populares produz um núcleo de bom senso e é a partir desse núcleo que deve iniciar-se o processo de transformação social.

O ponto de partida da filosofia da práxis é esse momento catártico de rearticulação crítica do senso comum, começando pela construção da autonomia dos setores subalternos até chegar à autonomia da sociedade entendida como totalidade, num processo de progressivo conhecimento em que se unificaram teoria e prática. Esse processo, evidentemente, não é espontâneo; uma massa humana não se torna autônoma sem organizar-se, e não existe organização sem intelectuais (1385).

A tarefa desses intelectuais especialistas é tanto introduzir a racionalidade mais avançada nas massas quanto potencializar o núcleo de bom senso. Assim, a relação entre a filosofia e a sociedade é garantida pela política (1383).

Como aponta Gonzalez:

"O intelectual orgânico de um grupo social subalterno que está rompendo com a rédea de hegemonias tradicionais formulará um novo projeto de relação com o senso comum, lugar onde age o "filósofo popular". Como procederá esse intelectual diante da consciência popular? Primeiro baseia-se nela, porque todos são filósofos. Não age dizendo: "venho trazer uma ciência nova, esqueçam todo o anterior"; pelo contrário, registra a atividade cultural já existente —vestígios de todas as formas anteriores de dominação, mas também de todas as formas anteriores de reflexão que podem ter servido como instrumento para se livrar dessa dominação. E depois, "de dentro" dela, tenta torná-la crítica; de "dentro" dela... porque não há pensamentos "falsos" ou "verdadeiros" em si mesmos, mas pensamentos que expressam com mais ou menos claridade a presença dos interesses de classe; no caso das classes produtivas e operárias, porque sua consciência social já contém pressupostos a partir dos quais se pode elevá-las a uma concepção superior de mundo. Esses elementos, se não estão já contidos na própria vida popular, não podem vir de nenhuma outra parte". (1981:95-96)

Através deste processo de relação orgânica com os grupos intelectuais a elas vinculados, as classes subalternas poderão construir um pensamento coerente e sistemático, e o bom senso é condição necessária desse processo. A incoerência atribuída por Gramsci ao senso comum está centrada nas diferenças entre pensamento racional e pensamento vulgar, sendo este último o 


\author{
trata-se de recuperar a vocação política da \\ universidade como possibilidade de construção \\ democrática de saberes, dentro de um \\ paradigma que enfatize a discussão de um \\ projeto societário radicalmente democrático
}

momento negativo do processo. O senso comum será sempre um primeiro momento incoerente e assistemático. A filosofia da práxis deve torna-lo unitário e coerente em sentido lógico, incorporando-o ao discurso plenamente racional.

Nesta mesma linha de recuperação do vínculo entre transformação superadora do senso comum e transformação social, Boaventura de Sousa Santos caracteriza o senso comum como uma racionalidade diferente da racionalidade científica. Assim, ele afirma:

"O senso comum faz coincidir causa e intenção; subjaz-Ihe uma visão do mundo assente na ação e no princípio da criatividade e das responsabilidades individuais. O senso comum é prático e pragmático; reproduz-se colado às trajetórias e às experiências de vida de um dado grupo social e nessa correspondência se afirma de confiança e dá segurança. O senso comum é transparente e evidente, desconfia da opacidade dos objetos tecnológicos e do esoterismo do conhecimento em nome do princípio da igualdade do acesso ao discurso, à competência cognitiva e à competência lingüística. O senso comum é superficial porque desdenha das estruturas que estão para além da consciência, mas, por isso, é exímio em captar a profundidade horizontal das relações conscientes entre as pessoas e entre pessoas e coisas. O senso comum é indisciplinar e metódico; não resulta de uma prática especificamente orientada para o produzir; reproduz-se espontaneamente no suceder quotidiano da vida. Por último, o senso comum é retórico e metafórico; não ensina, persuade". (1991:56)

Santos procura "salientar a positividade do senso comum, o seu contributo possível para um projeto de emancipação cultural e social" (1989:41). Ora, o desenvolvimento pleno das potencialidades valiosas do senso comum somente poderá acontecer na configuração de um tipo de conhecimento que ainda está em construção. Um conhecimento que deve conciliar a ciência com outros tipos de racionalidade.

Trata-se de recuperar a vocação política da universidade como possibilidade de construção democrática de saberes, dentro de um paradigma que enfatize a discussão de um projeto societário radicalmente democrático que deverá articular os diferentes elementos presentes (conflitos, demandas, interesses, idiossincrasias) na pluralidade dos sujeitos sociais. No que se refere à extensão temos salientado as suas potencialidades que provém da sua peculiar proximidade com as demandas sociais, o que deveria colocar esta atividade à frente do processo de formação, mas o que acontece na universidade é justamente o contrário, a sua obstinada subordinação.

\section{Referências bibliográficas}

Chauí, M. (2003). A universidade pública sob nova perspectiva. Em Revista Brasileira de Educação, 24, 5-15.

Chauí, M. (2001). Escritos sobre a universidade. São Paulo: Unesp.

Dagnino, E. et al. (Org.) (2006). A disputa pela construção democrática na América Latina. São Paulo: Paz e Terra.

Fórum de Pró-Reitores de Extensão das Universidades Públicas Brasileiras E Sesu / Mec. (2000/2001). Plano Nacional de Extensão Universitária. Brasil. Edição Atualizada.

Gonzalez, H. (1981). O que são intelectuais. São Paulo: Brasiliense.

Gramsci, A. (1981). Quaderni del Carcere: edizione critica dell'Istituto Gramsci a cura di Valentino Gerratana. Torino: Einaudi.

Laclau, E. (1986). Os Novos Movimentos Sociais e a Pluralidade do Social. Em: Revista Brasileira de Ciências Sociais, (02).

Laclau, E.; Mouffe, C. (1987). Hegemonía y estrategia socialista: Hacia una radicalización de la democracia. Madrid: Siglo XXI.

Mouffe, C. (1999). El retorno de lo político: Comunidad, ciudadanía, pluralismo, democracia radical. Barcelona: Paidós.

Nun, J. (1989). La rebelión del coro: Estudios sobre la racionalidad política y el sentido común. Buenos Aires: Nueva Visión.

Sousa Santos, B. de (2005). A Universidade no Século XXI: Para uma reforma democrática e emancipatória da Universidade. São Paulo: Cortez.

Sousa Santos, B. de (1997). Pela mão de Alice: O social e o político na pós-modernidade. São Paulo: Cortez. 